\title{
Sciendo
}

DOI 10.2478/afepuc-2019-0003

(C) Acta Facultatis Educationis Physicae Universitatis Comenianae 2019, 59(1): 21-32

\section{DEVELOPING EXPERTISE IN SPORT COACHING THROUGH ENGAGEMENT WITH DISABILITY PROGRAMMES}

\author{
Philippe Crisp \\ Institute of Sport, University of Chichester, Great Britain
}

\begin{abstract}
Summary: Numerous academic and practitioner research has examined the role of Higher Education Institutions (HEI) in the development of sport coaches in the UK (e.g. Crisp 2018; Stoszkowski and Collins 2018). However, whilst most fields related to coach development have significant bodies of work underpinning them, there is a dearth of information related to best practice within the context of disability sport coaching. Given that both coach learning in the HEI context and disability sports coaching are significant areas worthy of further exploration, this work investigates how learning can be developed through disability sport coaching in the HEI context. The aims of this study were to gather the perceptions, thoughts, and experiences of ten student-coaches enrolled on an HEI coaching programme who were completing a year long placement module that included sessions for participants with disabilities. Data were collected through two focus group meetings with the student-coaches and the submission of learning journals. Inductive analysis showed that coaching disability groups facilitated learning through generating knowledge from practice through a process of reflection, higher order thinking, and meta-cognition. This suggests that using disability coaching can be a useful tool for HEIs to use in terms of challenging student-coach practice and education.
\end{abstract}

Key words: sports coaching, meta-cognition, disability, reflection, coach-learning 


\section{Introduction}

This study illustrates the findings of an evaluation of student experiences/perceptions across a programme of disability coaching within a Higher Education Institute (HEI) coaching placement module. The central aim of this research was to assess the effectiveness, and resultant satisfaction, of the students' learning journey regarding the community programmes that they assisted in on site (at the University) as part of a one year coaching placement module. In addition to this broad aim, the purpose of the study was threefold: To identify key learning dispositions within this cohort of student-coaches related to the theories, skills and knowledge which sports coaches use in their work; to examine whether the students' personal capacities, knowledge and process skills related to learning and coaching are developed in the context of disability coaching; and to use this analysis to examine the extent to which independent learning and meta-cognition play in the development of student learning. What comes next is a more thorough outline of coaching skills and practice, and an overview of disability sports coaching in the UK.

\section{Coaching skills, coaching practice}

At a basic level, the nature and practice of sports coaching can be reduced to what might be considered minimum standards for deployment, with certain key elements such as leadership, planning, and communication to the fore (North 2009; Navin 2011;). However, understanding what sports coaching is, how to define it, and outlining what are considered to be the necessary core skills for delivery can prove to be problematic. This is particularly so once we add in the conundrum of coaching 'others' who are different to ourselves and that we have no experience of working with.

However, the use of the term the coaching process is helpful. This refers to the way in which performance, be it a specific skill, technique, or even the way in which someone can interact with others, is improved through a relationship between coach and performer (Cross \& Lyle 2003; Lyle 2008; Robinson 2010). So there is a clearly established recognition of how we can approach any understanding of sports coaching, perhaps irrespective of where it sits in a diverse and wide scope. Nevertheless, there continues to be an awareness within sports coaching literature that the organisational culture and provision of disability coaching is lacking (Townsend et al. 2015). Few may dispute this belief, and much of this is due to the acknowledgement that sport coaches, in the UK, have limited knowledge about impairment 
and disability. This is certainly true in the sense that the width and scope of disability coaching needs to first consider how disabilities are conceptualised.

\section{Disability coaching}

Disabilities are explained through the medical model, one that fundamentally positions disability through the lens of impairment (Shakespeare 2006) and the social model, one that sees disability as a product of society (Antonak \& Livneh 2000). The key tenet here is that society decides on the categories that are enabling and disabling. Both models include physical and learning impairments and given this, it is possible to surmise that working with people with impairments necessitates a focus on knowledge, context, and the developmental needs of coaches and organisations.

We can consider that anyone working with people with disabilities should have the capacity to understand context, diagnose issues and find solutions. Yet this suggests that these same 'workers' have a suitable breadth of experience, knowledge, and prior practice. In all likelihood, many sports coaches' learning in the UK will not have been augmented by any significant training programme/s specifically related to disability sports. The perennial problem then lies in how individuals need to draw from previous experiences and understanding of contexts, in this case various ones related to disability, in order to demonstrate expertise. But given the dearth of training available (certainly in the context of UK sports coaching), and the wide, shifting, complexities of defining and thus understanding disabilities, this proves to be a particularly unique problem. Whilst there is some literature pertaining to sport and disability, much of it is centred on performance sport (White \& Duda 1993; Townsend et al. 2015), carers (Melville et al. 2009) and teachers (Belley-Ranger et al. 2016).

In all likelihood coaches, or indeed anyone, will probably feel less enabled and more constrained in their working practice with people with disabilities if they have not received prior training; or do not fully understand the very construct of disability itself (Duarte \& Culver 2014; Townsend et al. 2015). Yet these are perennial problems that present themselves across a variety of relationships with people from all spectrums of ability, or disability.

In sum then, whilst we can look to define coaching and disability sports coaching, there remains the continuing issue of how best we can develop coaches within the context of disability. The next section looks to extend this by outlining coach education practice, assessment, and effectiveness - with a focus on learning in HEIs. 


\section{Coach learning and the role of UK HEI's}

The manner in which sports coaches learn best is articulated well through Cushion et al.'s (2010) systematic review of coach learning literature and the resultant schema they presented. Here the current understanding is that, as well as formal (most significantly through the mechamism of national governing body awards and official accreditation) and non-formal learning (an approach that incorporates a variety of methods such as workshops, small courses and general continuous professional development), the role of informal coach learning seems to be more significant in developing coaches. This approach, one that incorporates relatively unstructured, non-accredited and non-assessed methods of learning, seeks to avoid what can be seen as systems learning that can perhaps offer just a limited parameter of skills and competencies to learn from (Jones et al. 2004; Gilbert \& Trudel 2006; Cushion et al. 2010; MacDonald et al. 2010; Crisp 2018). This focus on non-formal learning highlights the way in which learners use self-directed and non-assessed learning that places reflection and experience first and foremost. The central premise of this approach is that this is the most effective way of learning meaningful skills and developing attributes.

In highlighting this idea of longer term learning, the fact that much of the formal coach education in the UK context takes place in what can be considered particularly short (in terms of contact hours) and/or compressed programmes at levels one and two (of a one to four model) reinforces what are seen as their potential shortcomings (Gilbert \& Trudel 2001; Mallett et al. 2009). These short courses, the necessary qualification levels for working in the UK, often take place over no more than two weekends, and are normally set up as programmes of grouplearning. These are facilitated by more experienced coaches who have been trained to help participants on the courses meet minimum requirements necessary (Cushion et al. 2010).

Much of this reliance on a formal coach education system, by its very nature, mitigates against the possibility of ensuring that a substantial engagement with the process of informal learning can take place. However degree courses, generally taken over three years in the UK, can specifically address engagement with longer learning processes by following designed learning opportunities and structures within this three year framework. Indeed, HEIs can, alongside developing what are seen as key transferable and critical thinking skills for graduates, support vocational and disciplinary identified core competencies for work related activities. For example, in the context of coaching, HEIs can offer supported coaching placements to extend opportunities for experiential learning to take place (Crisp 2018).

These extended opportunities allow a greater, deeper engagement with the process of reflection, something seen as key to accumulating knowledge and iterating through a cycle of 
experience, reflection and action (Schön 1987; Knowles et al. 2006). One widely acknowledged consequence of using and adhering to reflective practice is that it develops greater self-awareness and offers opportunities for participants, in particular to develop strategies that help orchestrate best practice in work. It is noteworthy then, that there is an interface between reflective practice and meta-cognition. The theory of meta-cognition is used to explain the deep level and self-regulated skill that develops awareness, and control, of learning (Poitras \& Lajoie 2013; Ferreira et al. 2015). The work of Flavian (2015), for instance, illustrates the way that metacognitive activities can be seen as "one's ability to monitor, control, set goals, regulate thinking, and reflect" (p. 92).

By considering these themes, we are able to see that similar patterns of active control over thinking processes and developing independent learning are evident within both reflection and meta-cognition (Biggs \& Tang 2007; Vickerman 2009). For example, the previously mentioned ability to develop strategies for improving learning and performance. Yet the issue concerning the development of coaches within the HEI system is not simply whether prolonged passages of reflection can contribute to achieving specific outcomes and knowing about one's own and others' thinking. Rather, it is asking how the higher order thinking involved in decision making and knowing what 'works' or might 'work' can be developed.

\section{Methodology}

The central aim of the study resulted in the formulation of the following three questions.

1. How can emerging, learning coaches in HE benefit from coaching and reflection over a one year module that includes the provision of regular external group coaching?

2. How do we determine the extent to which core coaching skills (i.e. communication, group management) of coaching can be developed within the context of disability?

3. What is the role, function, and impact of meta-cognition in developing effective student/coach learning?

These questions were explored by cataloguing and then analysing the perceptions and experiences of ten student-coaches enrolled on a HEI coaching programme. Specifically, these ten student-coaches were all involved in the direct delivery of a community engagement programme, run under the auspices of a one year coaching placement module, that focused in significant part on participants with disabilities. Criterion for the participants in the present study included that they had: a) never coached people with disabilities before, b) still 
considered themselves to be 'learner-coaches' (defined by the fact all had less than one year's part time coaching experiences and that all of them had no higher than a Level 1 equivalent coaching qualification) and c) by the end of the module had all completed at least 30 hours of direct coaching (leading sessions) within this disability programme.

The data collection began in earnest near to the end of the module when two focus groups and evaluations were held. In these the student-coaches were asked to clarify their views regarding the module, as well as asked to define specific advantages or disadvantages they might have gained from participating in the disability programme. Additionally, the studentcoaches submitted reflective journals as part of their module assessment, and the information in these relating to their development and perceptions of taking part in the disability programmes were compared and combined with the data from the two focus groups in order to identify the key words, responses and phrases that kept appearing across them all. The key themes, codes, and patterns were then aggregated into three main sections that were considered to represent the totality of the central topics. These were: 'Time - continued delivery, reflection, and meta-cognition' and 'Configuring individual practice: Meta-cognition'.

\section{Results/discussion}

\section{Time - continued delivery and reflection}

Time, in the context of the student-coaches in the present study, was considered to be a hard won commodity. Given the pressures of various student, work, family, sport, and recreational demands, it was extremely difficult for the student-coaches to actively engage with periods of self-reflection. This meant that the process of experiential learning proved to be difficult to implement without opportunities to actively reflect on what they had done, and their practice as a whole. Having the opportunity to talk, practice, and reflect with a group of other coaches was warmly welcomed. One student-coach (number two) described this opportunity as a particularly helpful interlude to much of the rest of the "chaos" that they were experiencing. Of particular note, they mentioned the difference between their own coaching placement (one that they had organised) and the one that the University offered on site:

SC2: "I believe that this experience has allowed me to see things from a different perspective, and not to take myself too seriously as a coach, a contrast from my primary placement and student life in general I faced many different challenges in my secondary 
placement compared to my primary placement. I found that my role as a coach changed completely."

Similarly, all the student-coaches stressed that the programmes helped facilitate a process of reflection that was essential to promoting change within their development and practice. An example here is how student-coach seven stated that.

SC7: "It also made me reflect afterwards, and how inspirational the people that took part in the sessions are, no matter what their disability was, they tried their hardest. Knowing this, it changed my outlook on coaching and that you cannot discriminate against anyone. When I first started coaching, I realised that coaching is being able to make instant decisions, where they need to have a rational decision behind them."

This type of analysis was consistent with many of the other student-coaches' feelings about how much being together for a set period of time helped. It became clear that the context of disability coaching within which they operated necessitated a significant commitment to group work and communication, all of which - irrespective of the nature and expertise of the respective student-coach - meant that coach learning was facilitated by the provision of time, mutual dependency, and reciprocity of support. In fact, the student-coaches' initial understanding of their limitations in developing their coaching craft was allied to the fact that they considered it particularly difficult to develop the skills necessary for self-reflection, given their time constraints. This acknowledgement of the considerable difficulties they faced were evident within the student-coaches' reflections, and were consistent across the whole cohort. Whilst some of this was, no doubt, due to the similarities in the developmental level of the learners, what was of note was that the time to develop the tools and "know-how" to coach was thought to be significantly lacking. Student-coach six explained this in detail.

SC6: "This placement was a fantastic opportunity to immerse myself in an area of coaching that I had never experienced before. What I really noticed was that it gave me the time and space to really think about what I was doing, alongside my fellow students. Whilst I do a fair amount of coaching outside of these programmes, that's all pretty much on my own, and I don't get the opportunity to work in a group or talk to other coaches who have the same needs as I do. I'd say the rewards have been noticeable."

These recollections related to the time that it took to more completely engage with a deeper development of knowledge. Many authors within the field of coach education are in agreement that accruing hours and reflecting on their practice is a cornerstone of how coaches can generate knowledge (Gilbert \& Trudel 2006; MacDonald et al. 2010). The findings in this study corroborate this, in the sense that the student-coaches felt that the time they needed to 
allocate to the planning and delivery for the community engagement sessions was very helpful. The times allocated here were, in fact, indicative of a system that whilst simplistic in nature, necessitated a more compartmentalised, contextualised and supported system of co-learning.

\section{Configuring individual practice: Meta-cognition}

Encouragingly, all of the student-coaches seemed aware that this issue of a lack of time was one that, whilst constraining in many respects, was also something that could be overcome with good planning:

SC1: "Since starting my coaching placements back in September, I have learnt a lot about myself, a lot more than I thought I would. Some things I learnt about coaching are more positive than others, as this coaching placement has opened my eyes to see things about finding the time to reflect and learn that I did not know were there." The whole cohort also agreed that as developing student-coaches they benefited from being placed in an environment where they needed to "make quick decisions about what to do" and use a mixture of different types of reflective practice "before, during, and after sessions". Student-coach ten explained how the contrast in their coaching roles between performance sport and disability/community sport made them realise that they had to mentally adapt to the different challenges they faced: "it made me stop, think, reflect, and react to the different type of sessions we needed, not just drill based or technique based".

The student-coaches also described how they needed consistent engagement with the practice of coaching, something that the programmes offered, to fully immerse themselves in the process of reflection. An example here is student-coach five that stated.

SC5: "When I was coaching on these programmes, I was actively using reflective practice, to make sure that I developed as a coach. I used a variety of different methods of reflective practice, the majority of this being clear reflection on the action through. Although for various sessions, I would analytically reflect, this would help me dissect my style of coaching, which at times was quite autocratic, and this was the right style for some of the participants." The present study earlier outlined the concept of meta-cognition, one that encapsulates deep learning and problem solving. Nisbet and Shucksmith (1986, p. 30) explain this concept as the ability to "to know about one's own knowing". Using this explanation allows us to understand how adherence to a set programme allowed a more complete, holistic engagement with the process of thinking. This is in terms of the aforementioned set programme, the times it took to plan, and the co-work that it necessitated. Indeed, much like Vickerman's (2009) argument that meta-cognition helps organise and amplify individual 
conceptions of how oneself and others think, the student-coaches thought that they were becoming, through the demands of the programme, more capable of appropriate decision making and contextualised thinking: all indicative of higher order thinking.

There is, however, one caveat left in terms of the community engagement programme. This is that the very fact that they were coaching participants with a variety of disabilities made them reflect, react, and consider different approaches to their practice. Student-coach two summed this up with their thoughts that.

SC2: "With the disability programmes, there's more to think about. Genuinely. You can't just have one way of coaching, you can't rely on one way of doing things, you do have to come up with a much bigger range of opportunities and ideas to implement. You've just got to think more about what you're doing and how you've done things. It's a great way of really making you focus and consider your overall coaching practice and behaviours."

In sum then, all of the student-coaches were using forms of deep reflection within their one year learning journey on a disability sport community engagement programme. Admittedly, at times this was in a less formal manner. For instance, one student-coach (nine) explained that whilst they had not specifically set out to consider their working practice, by the end they believed they had "strongly developed as a person with changing environments". In all, all of the student-coaches had explicitly valued the time, support, and ability to co-work and reflect over a long period of time. One student-coach (four), for instance, stated that the community engagement project had helped them "considerably develop as a coach from when I first started", and that they had "grown in confidence because of my greater ability to think about what I do". Here, these recollections have shown how the use of meta-cognition can make sense of the deeper, more self-regulated skill of reflection and determining strengths, weaknesses, and individual practice beyond isolated theory (Biggs \& Tang 2007; Ozsoy et al. 2009; Vickerman 2009). Subsequently, meta-cognition can quite consistently help explain the enduring application of deeper level thinking that the student-coaches engaged with, in this instance facilitated by working in the community engagement programme.

\section{Conclusion}

In this paper I have sought to explain the views, recollections, and learning journey of ten student-coaches on an HE coaching programme. Their perspectives revealed several particularly salient features regarding the pre-eminence of deep reflection and mutual 
dependency within the learning process, and also strongly suggested that taking part in coworking within learning was highly effective in developing their practice and contributing to their personal satisfaction. Whilst the significance of this might not lead to any substantive change in the way that their views and practices develop, the manner in which they could focus on learning undertaken through the prism of disability certainly held some significant promise in terms of the development of alternative coach-learning practices. Finally, the data from this study demonstrated that the continual engagement in the programme of learning and the programme of disability coaching seemed to emphasise, and enable, the use of deeper, critical thinking and meta-cognition.

However, although the current study offers new ways of considering coach-learning, it is not without its limitations. Given the small sample size the results of this study may not be applicable or generalisable to other groups. And whilst the qualitative approach led to a deep and thoughtful level of understanding, the data is based on personal recollections and as such, may have involved a degree of personal bias. A recommendation would be for future research to develop and build upon the findings of this study by examining the impact that disability coaching can have on larger cohorts, and potentially more experienced coaches.

In essence then, the paper presents evidence that coach practice and learning, in the context of sport, participants, and provision, needs to recognise that the use of disability coaching to enhance core coaching skills can lead to more marked performance levels in terms across coaching domains, as well as lead to a deeper awareness and critical self-reflection.

\section{References}

1. ANTONAK, R. F. \& H. LIVNEH, 2000. Measurement of attitudes towards persons with disabilities. In: Disability and Rehabilitation. 22, pp. 211-224.

2. BELLEY-RANGER, E., H. CARBONNEAU, R. ROULT, I. BRUNET, M. DUQUETTE \& E. NAUROY, 2016. Determinants of Participation in Sport and Physical Activity for Students with Disabilities According to Teachers and School-based Practitioners Specialized in Recreational and Competitive Physical Activity. In: Sport Science Review. 25, pp.135-158.

3. BIGGS, J. \& C. TANG, 2007. Teaching for Quality Learning at University. Maidenhead: Open University Press. ISBN 978-0335242758. 
4. CRISP, P., 2018. Coaching placements and incidental learning - how reflection and experiential learning can help bridge the industry skills gap. In: Journal of Learning Development in Higher Education. 3, pp.1-28.

5. CROSS, N. \& J. LYLE, 2003. The Coaching Process. Edinburgh: Butterworth Heinemann. ISBN 978-0750641319.

6. CUSHION, C., N. NELSON, K. ARMOUR, J. LYLE, R. JONES, R, SANDFORD \& C. O’CALLAGHAN, 2010. Coach Learning \& Development: A Review of Literature. Leeds: Sports Coach UK.

7. DUARTE, T., \& D. CULVER, 2014. Becoming a coach in developmental adaptive sailing: A lifelong learning approach. In: Journal of Applied Sport Psychology. 26, pp. 441-456.

8. FERREIRA P. C., A.M. VEIGA-SIMAO \& A. LOPES DA SILVA, 2015. Does training in how to regulate one's learning affect how students report self-regulated learning in diary tasks? In: Metacognition and Learning. 10, pp. 199-230.

9. FLAVIAN, H., 2016. Towards teaching and beyond: Strengthening education by understanding students' self-awareness development. In: Power and Education. 8, pp. 88100.

10. GILBERT, W., \& P. TRUDEL, 2006. The coach as a reflective practitioner. In: JONES, R.L. The sports coach as educator: Re-conceptualising sports coaching. Oxon: Routledge, pp. 113-127. ISBN 978-0415367608.

11. JONES, R. L, K. ARMOUR \& P. POTRAC, 2004. Sports coaching cultures: From practice to theory. London: Routledge. ISBN 0-415328527.

12. KNOWLES, Z., G. TYLER, D. GILBOURNE \& M. EUBANK, 2006. Reflecting on reflection: exploring the practice of sports coaching graduates. In: Reflective Practice. 7, pp. $163-179$.

13. LYLE, J., 2008. Sports Development and Sports Coaching. In K.HYLTON \& P. BRAMHAM. Sports Development: Policy, process and practice. London: Routledge, pp. 214-235. ISBN 0-419260102.

14. MACDONALD, D. J., J. CÔTÉ \& J. DEAKIN, 2010. The Impact of Informal Coach Training on the Personal Development of Youth Sport Athletes. In: International Journal of Coaching Science. 5, pp. 363-372.

15. MALLETT, C., P. TRUDEL, J. LYLE \& S. RYNNE, 2009. Formal vs informal coach education. In: International Journal of Sports Science and Coaching. 4, pp. 325-334. 
16. MELVILLE, C. A., S. HAMILTON, S. MiLlER et al., 2009. Carer Knowledge and Perceptions of Healthy Lifestyles for Adults with Intellectual Disabilities. In: Journal of Applied Research in Intellectual Disabilities. 22, pp. 298-306.

17. NAVIN, A., 2011. Sports Coaching: A Reference Guide for Students, Coaches, and Competitors. Ramsbury: The Crowood Press. ISBN 978-1847971937.

18. NISBET, J. \& J. SHUCKSMITH, 1986. Learning Strategies. London: Routledge and Kegan Paul, ISBN 978-1138732049.

19. NORTH, J., 2009. The UK Coaching Framework: The Coaching Workforce 2009-16. Leeds: Coachwise.

20. OZSOY, G., A. MEMIS \& T. TEMUR, 2009. Metacognition, study habits and attitudes. In: International Electronic Journal of Elementary Education. 2, pp. 154-166.

21. POITRAS E. G \& S. P. LAJOIE, 2013. A domain-specific account of self-regulation learning: The cognitive and metacognitive activities involved in learning through historical inquiry. In: Metacognition and Learning. 8, pp. 213-234.

22. ROBINSON, P. E., 2010. Foundations of Sport Coaching. London: Routledge, ISBN 9780415469715.

23. SCHÖN, D., 1987. Educating the reflective practitioner: Toward a new design for teaching and learning in the professions. San Francisco: Josey-Bass. ISBN 978-1857423198.

24. SHAKESPEARE, T., 2006. Disability rights and wrongs. London: Taylor \& Francis. ISBN 978-0415347198.

25. STOSZKOWSKI, J. \& D. COLLINS, 2018. The Agony and the Ecstasy: Student-Coaches' Perceptions of a Heutagogical Approach to Coach Development. In: International Sport Coaching Journal. 5, pp.136-144.

26. TOWNSEND, R. C., B. SMITH \& C. CUSHION, 2015. Disability sports coaching: towards a critical understanding. In: Sports Coaching Review. 4, pp. 80-98.

27. VICKERMAN, P., 2009. Student perspectives on formative peer assessment: An attempt to deepen learning? In: Assessment and Evaluation in Higher Education. 34, pp. 221-230.

28. WHITE, S. A \& J. L. DUDA, 1993. Dimensions of Goals and Beliefs among Adolescent Athletes with Physical Disabilities. In: Adapted Physical Activity Quarterly. 10, pp.125136. 